\title{
Dual-Energy X-Ray Computed Tomography Scanner Using Two Different Energy-Selection Electronics and a Lutetium-Oxyorthosilicate Photomultiplier Detector
}

\author{
Osahiko Hagiwara1, Eiichi Sato ${ }^{2 *}$, Yasuyuki Oda², Satoshi Yamaguchi' ${ }^{3}$, Yuichi Sato ${ }^{4}$, \\ Hiroshi Matsukiyo ${ }^{1}$, Toshiyuki Enomoto', Manabu Watanabe1, Shinya Kusachi1 \\ ${ }^{1}$ Department of Surgery, Toho University Ohashi Medical Center, Tokyo, Japan \\ ${ }^{2}$ Department of Physics, Iwate Medical University, Yahaba, Japan \\ ${ }^{3}$ Department of Radiology, School of Medicine, Iwate Medical University, Morioka, Japan \\ ${ }^{4}$ Central Radiation Department, Iwate Medical University Hospital, Morioka, Japan \\ Email: *dresato@iwate-med.ac.jp
}

How to cite this paper: Hagiwara, O., Sato, E., Oda, Y., Yamaguchi, S., Sato, Y., Matsukiyo, H., Enomoto, T., Watanabe, M. and Kusachil, S. (2017) Dual-Energy X-Ray Computed Tomography Scanner Using Two Different Energy-Selection Electronics and a Lutetium-Oxyorthosilicate Photomultiplier Detector. International Journal of Medical Physics, Clinical Engineering and Radiation Oncology, 6, 266-279.

https://doi.org/10.4236/ijmpcero.2017.63024

Received: May 26, 2017

Accepted: July 29, 2017

Published: August 1, 2017

Copyright $(9) 2017$ by authors and Scientific Research Publishing Inc. This work is licensed under the Creative Commons Attribution International License (CC BY 4.0).

http://creativecommons.org/licenses/by/4.0/

\begin{abstract}
To obtain two kinds of tomograms at two different X-ray energy ranges simultaneously, we have constructed a dual-energy X-ray photon counter with a lutetium-oxyorthosilicate photomultiplier detector system, three comparators, two microcomputers, and two frequency-voltage converters. X-ray photons are detected using the detector system, and the event pulses are input to three comparators simultaneously to determine threshold energies. At a tube voltage of $100 \mathrm{kV}$, the three threshold energies are 16, 35 and 52 $\mathrm{keV}$, and two energy ranges are $16-35$ and $52-100 \mathrm{keV}$. X-ray photons in the two ranges are counted using microcomputers, and the logical pulses from the two microcomputers are input to two frequency-voltage converters. In dual-energy computed tomography (CT), the tube voltage and current were $100 \mathrm{kV}$ and $0.29 \mathrm{~mA}$, respectively. Two tomograms were obtained simultaneously at two energy ranges. The energy ranges for gadolinium-L-edge and K-edge CT were $16-35$ and $52-100 \mathrm{keV}$, respectively. The maximum count rate of dual-energy CT was 105 kilocounts per second with energies ranging from 16 to $100 \mathrm{keV}$, and the exposure time for tomography was $19.6 \mathrm{~min}$.
\end{abstract}

\section{Keywords}

X-Ray Photon Counting, LSO-PMT Detector, Dual-Energy Counter, EnergyDispersive CT, Gd-L-Edge CT, Gd-K-Edge CT 


\section{Introduction}

Monochromatic parallel X-ray beams [1] [2] are produced using a synchrotron and silicon single crystals and have been applied to perform enhanced iodine (I) $\mathrm{K}$-edge angiography. Using this imaging, fine coronary arteries below $100 \mathrm{mi}$ crons in diameter can be observed at high contrasts. Therefore, we developed a cerium X-ray generator [3] to carry out I-K-edge imaging, since cerium K photons are absorbed effectively by I atoms.

Recently, quasi-monochromatic X-ray imaging can be performed utilizing a photon-counting energy-dispersive method, and several energy-dispersive cameras [4] [5] have been developed. Next, preclinical energy-dispersive computed tomography (CT) scanners [6] [7] [8] have been developed using cadmium telluride (CdTe) array detectors. In this regard, we are developing an energy-dispersive CT scanner using a dual-energy CdTe array detector [9] to perform high-speed energy-dispersive CT.

To carry out fundamental experiments concerning the K-edge CT using I and gadolinium (Gd) media, we constructed several first-generation energy-dispersive CT scanners [10] [11] [12] using CdTe detectors for measuring X-ray spectra. Using these scanners, thick blood vessels are observed at high contrasts, since the energy resolution has been improved to approximately $1 \%$ at $122 \mathrm{keV}$. However, the maximum count rate of the CdTe detector is 5 kilocounts per second (kcps) without pileups of the event signals.

In the first-generation energy-dispersive $\mathrm{CT}$, various $\mathrm{X}$-ray detectors can be used, and the count rate has been increased beyond 1 megacounts per second [13] using short-decay-time scintillation crystals and multipixel photon counters at a constant temperature; the sensitivity depends on the temperature. Next, scintillation detector using a small photomultiplier tube (PMT) is also useful for detecting X-ray photons with high count rates, and the sensitivity seldom varies at room temperature.

The PMT-scintillation detector is usually used to measure high-energy $\gamma$-ray spectra [14], and low-energy X-ray spectra used in medical radiography with energies below $150 \mathrm{keV}$ can be measured by reducing the dark count rate of the PMT. In this regard, zero-dark-counting can be performed by increasing the time constant of the amplifying circuit for producing event pulses.

To increase the photon count rate without the dark counts, the time constant of the amplifier for the photomultiplier should be regulated beyond $100 \mathrm{~ns}$; a 100-ns-constant amplifier never amplifies 10-ns-width dark pulses. Using a multichannel analyzer, the X-ray spectra can be measured by the pulse-height analysis. However, the pulse height measured decreases with reducing the event pulse width owing to the sampling period using the multichannel analyzer and the photon counter with comparators. Therefore, the pulse-width extender is useful for determining the threshold energies correctly using the comparators in the cases where the pileups are not occurred.

In our research, our major objectives are as follows: to develop a dual-energy $\mathrm{X}$-ray photon counter, to increase the count rate using a lutetium-oxyorthosili- 
cate (LSO) photomultiplier detector, to improve the spatial resolution using a lead pinhole, and to obtain Gd-L- and K-edge tomograms simultaneously. Therefore, we constructed a novel energy-dispersive counter with the LSOphotomultiplier detector system and three comparators and performed dualenergy CT operated at a tube voltage of $100 \mathrm{kV}$ and a current of $0.29 \mathrm{~mA}$.

\section{Methods}

\subsection{DE Photon Counting}

Figure 1 shows a block diagram of dual-energy (DE) X-ray photon counting. $\mathrm{X}$-ray photons passing through a $0.5-\mathrm{mm}$-diam $3.0-\mathrm{mm}$-thick lead pinhole are detected by the LSO single crystal with a decay time of $40 \mathrm{~ns}$, and the scintillation photons are detected using a small PMT (Hamamatsu, H10721P-110). The LSO crystal of $5.0 \times 5.0 \times 1.0 \mathrm{~mm}^{3}$ is positioned on the photoelectric glass surface just outside the photocathode in the PMT using a grease. The crystal is covered with a brass cap with a $25-\mathrm{mm}$-thick aluminum window to shade visible rays. The DE counter consists of the LSO-PMT detector, an inverse high-speed voltage-voltage $(\mathrm{V}-\mathrm{V})$ amplifier, a pulse-width extender, three comparators (STMicroelectronics, TS3022), two microcomputers (MCs; Atmel, ATMEGA168P-20PU), and two frequency-voltage converters (FVCs). X-ray photons are detected using the detector, and the negative output pulses produced in the PMT are amplified using the V-V amplifier. The 200-ns-width event pulses from the amplifier are input to the pulse extender with a 1- $\mu$ s-timeconstant integrator, and the output pulses are sent to three comparators simultaneously to select three threshold energies of 16,35 and $52 \mathrm{keV}$. The MC1 selects photons at an energy range between 16 and $35 \mathrm{keV}$, and the MC2 counts photons beyond $52 \mathrm{keV}$. Subsequently, logical pulses from each MC are sent to

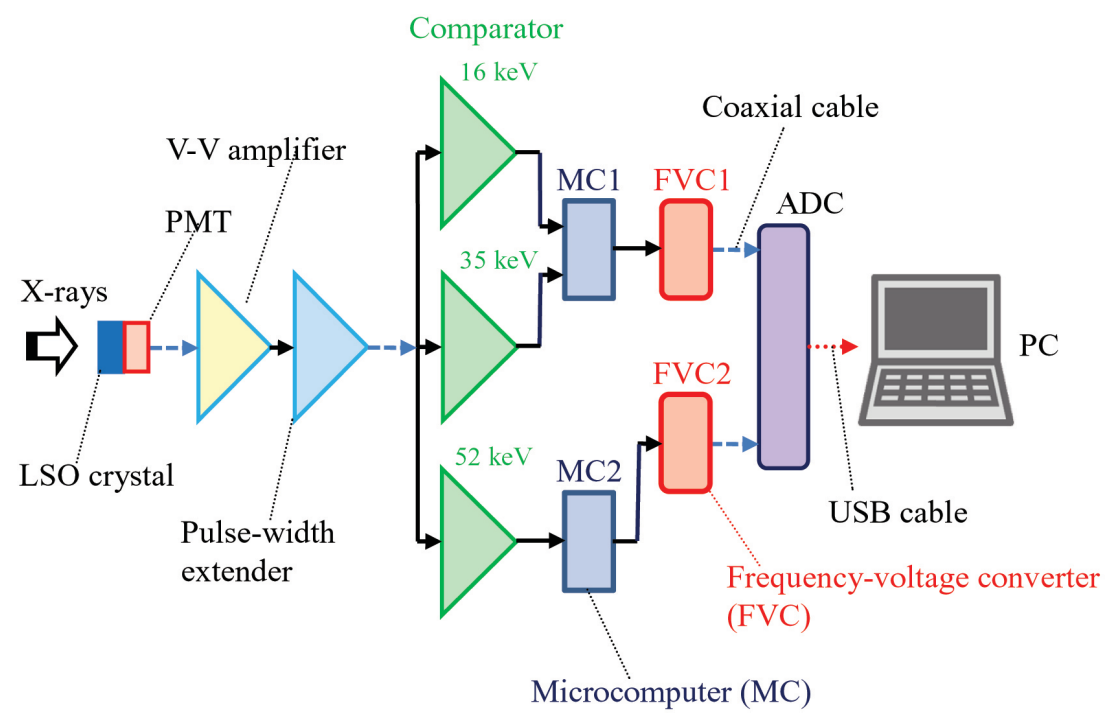

Figure 1. Block diagram of DE photon counting using an LSO-PMT detector, a V-V amplifier, a pulse-width extender, three comparators, and two sets of MCs and FVCs. The $\mathrm{MC1}$ performs photon-count energy subtraction in the photon-energy range between 16 and $35 \mathrm{keV}$, and the MC2 counts photons with energies beyond $52 \mathrm{keV}$. 
the FVC to convert count rates into voltages, and the FVC outputs are sent to a personal computer through an analog to digital converter (ADC; Contec, AI-1608AY-USB) to reconstruct tomograms.

The circuit diagram of the $\mathrm{V}-\mathrm{V}$ amplifier is shown in Figure 2. To perform zero-dark counting, we used an $80 \mathrm{MHz}$ band-width operational amplifier (Analog Devices, AD8032) and a 200-ns-time-constant differentiator. The negative PMT outputs are input to the first inverse $\mathrm{V}-\mathrm{V}$ amplifier, and the outputs are sent to a second $\mathrm{V}-\mathrm{V}$ amplifier through the differentiator for cutting wave tails. Therefore, approximately 10-ns-width dark counts from the PMT are not detected at all, and only photons including $\gamma$-rays from the LSO can be de-

(a)

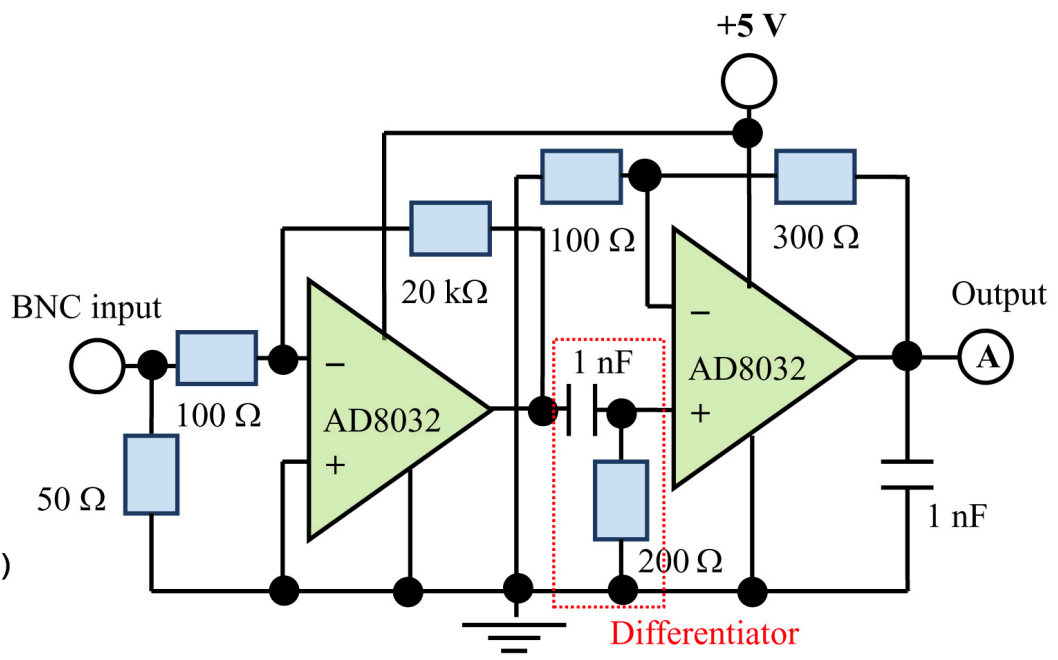

(b)

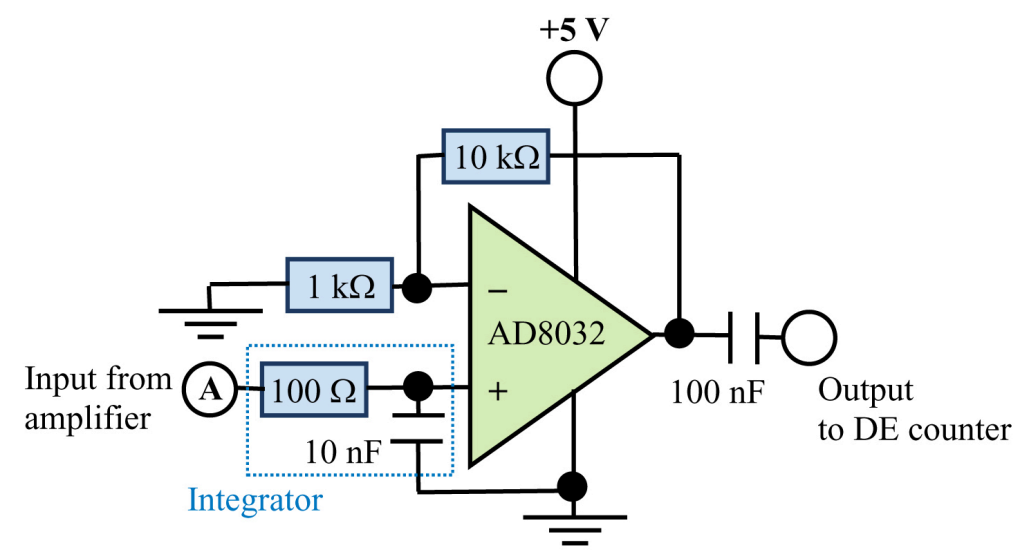

(c)

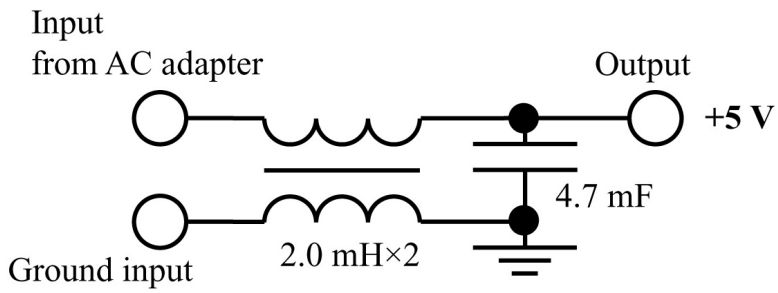

Figure 2. Circuit diagrams of (a) the inverse V-V amplifier with a differentiator, (b) the pulse-width extender with an integrator, and (c) a smoothing circuit consisting of a common-mode inductor and a large-capacity condenser. 
tected. Although the 200-ns-event pulses can be counted using the DE counter, the pulse width extender is useful for determining the threshold energies without calibration. To drive both the amplifier and the extender, a smoothing circuit consisting of a common mode inductor and a large-capacity condenser is useful.

Figure 3 shows the block diagram of the FVC. The FVC is used to convert count rates into voltages and to improve the image granulation. In each FVC, the logical pulses from the MC are shaped into long pulses and piled up using the first integrator with a time constant of $36 \mathrm{~ms}$, and the voltage is amplified using a V-V amplifier. The second 24-ms integrator is used to reduce the electric noises.

\subsection{DE-CT Scanner}

An experimental setup of the DE-CT scanner is shown in Figure 4. The scanner consists of an X-ray generator (R-tec, RXG-0152), a turntable (Siguma Koki, SGSP-60YAW-OB), a scan stage (Siguma Koki, SGSP-26-100), a two-stage controller (Siguma Koki, SHOT-602), and the LSO-PMT detector. The distance between the X-ray source and the detector is $1.00 \mathrm{~m}$. The distance from the center of turntable to the detector is $0.20 \mathrm{~m}$, and the lead pinhole is set in front of the LSO-PMT detector to improve the spatial resolution.

In this scanner, both the X-ray source and the detector are fixed, and the object on the turntable oscillates on the scan stage with a velocity of $25 \mathrm{~mm} / \mathrm{s}$ and a stroke of $60 \mathrm{~mm}$. The X-ray projection curves for tomography are obtained by

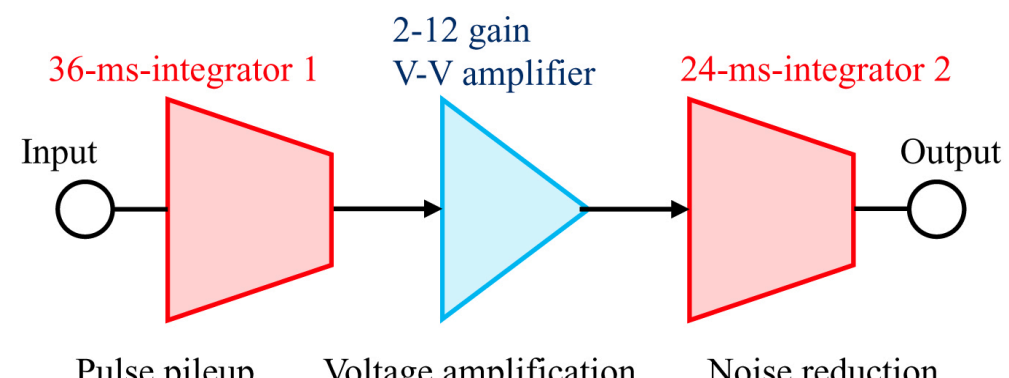

Figure 3. Block diagram of the FVC consisting of two integrators and a V-V amplifier.

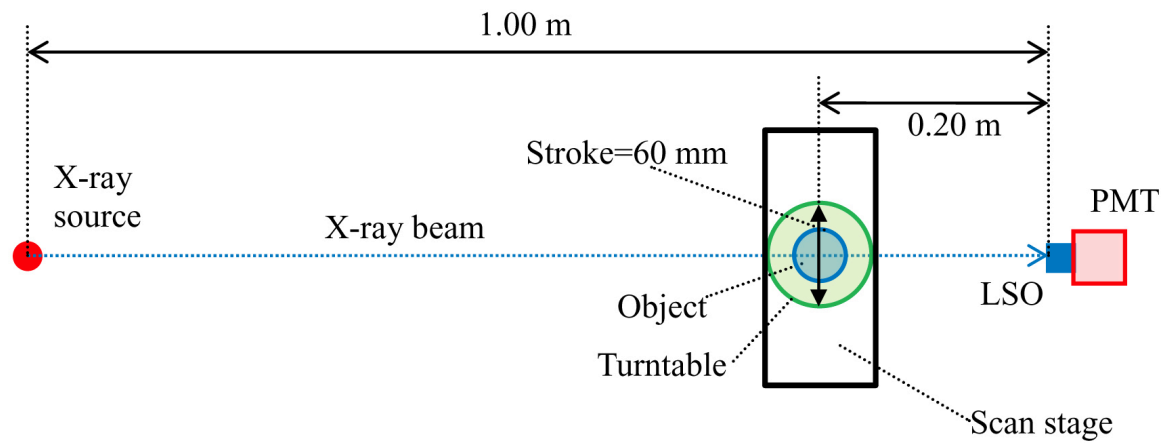

Figure 4. Experimental setup of the main components in the DE-CT scanner. The DE$\mathrm{CT}$ is performed by repeated linear scans and rotations of the object using the LSO-PMT detector. 
repeated linear scans and rotations of the object, and the scanning is conducted in both directions of its movement. Two step values of the linear scan and rotation are selected to be $0.5 \mathrm{~mm}$ and $1.0^{\circ}$, respectively. Using this DE-CT scanner, the exposure time is $19.6 \mathrm{~min}$ at a total rotation angle for CT of $360^{\circ}$.

\subsection{Measurements of X-Ray Dose Rate and Spectra}

The measurement of X-ray dose rate is important to calculate incident dose for patients. The X-ray dose rate from the X-ray generator was measured using an ionization chamber (Toyo Medic, RAMTEC 1000 plus) at a tube current of 0.29 $\mathrm{mA}$ without filtration. The chamber was placed $1.0 \mathrm{~m}$ from the X-ray source, and we measured the dose rate with changes in the tube voltage from 70 to 110 $\mathrm{kV}$.

To measure standard X-ray spectra for reference with changes in the tube voltage, we used a readily available CdTe detector (Amptek, XR100-T) with a 0.5 - $\mathrm{mm}$-diam lead pinhole placed $1.0 \mathrm{~m}$ from the $\mathrm{X}$-ray source. The event pulses from the shaping amplifier are input to a multichannel analyzer (MCA; $\gamma$ PGT, MCA4000) to perform pulse-height analysis. The photon energy was determined by one-point calibration using an energy of tungsten (W) $\mathrm{K} \alpha$ photons.

Using the LSO-PMT detector in the DE-CT scanner, we also measured X-ray spectra. The detector with a $0.5-\mathrm{mm}$-diam lead pinhole was set $1.0 \mathrm{~m}$ from the $\mathrm{X}$-ray source. The output pulses from the pulse extender are input to the MCA, and the photon energy was determined by four-point calibration. The major calibration was performed using $\mathrm{I}-\mathrm{K}(28.5 \mathrm{keV})$ and $\mathrm{W}-\mathrm{K}(58.9 \mathrm{keV})$ photons. Next, we measured the remaining count at an energy of $50 \mathrm{keV}$ and a tube voltage of $50 \mathrm{kV}$, and the count was applied to the two maximum bremsstrahlung energies of 75 and $100 \mathrm{keV}$ to roughly calibrate the energy; the detector sensitivity varied beyond the Lutetium ( $\mathrm{Lu}) \mathrm{K}$ edge of $63.3 \mathrm{keV}$. At a tube voltage of 50 $\mathrm{kV}$, the remaining count on an energy of $50 \mathrm{keV}$ was caused by low-energy resolution and had a value of 260 count.

\subsection{Real Animal Phantoms}

In the DE-CT, we used real dog-heart and rabbit-head phantoms. These phantoms were made approximately twenty years ago, and the operation on animals was carried out in accordance with the animal experiment guidelines of our university.

\section{Results}

\subsection{X-Ray Dose Rate and Spectra}

Figure 5 shows the X-ray dose rate at a constant tube current of $0.29 \mathrm{~mA}$. X-ray dose rate increased with increasing tube voltage. At a tube voltage of $100 \mathrm{kV}$, the $\mathrm{X}$-ray dose rate was $26.7 \mu \mathrm{Gy} / \mathrm{s}$ with a standard deviation of $0.1 \mu \mathrm{Gy} / \mathrm{s}$.

The standard X-ray spectra measured using the CdTe detector are show in Figure 6. Both the maximum and the bremsstrahlung-peak energies increased with increasing tube voltage from 50 to $100 \mathrm{kV}$. At a tube voltage of $100 \mathrm{kV}$, we 


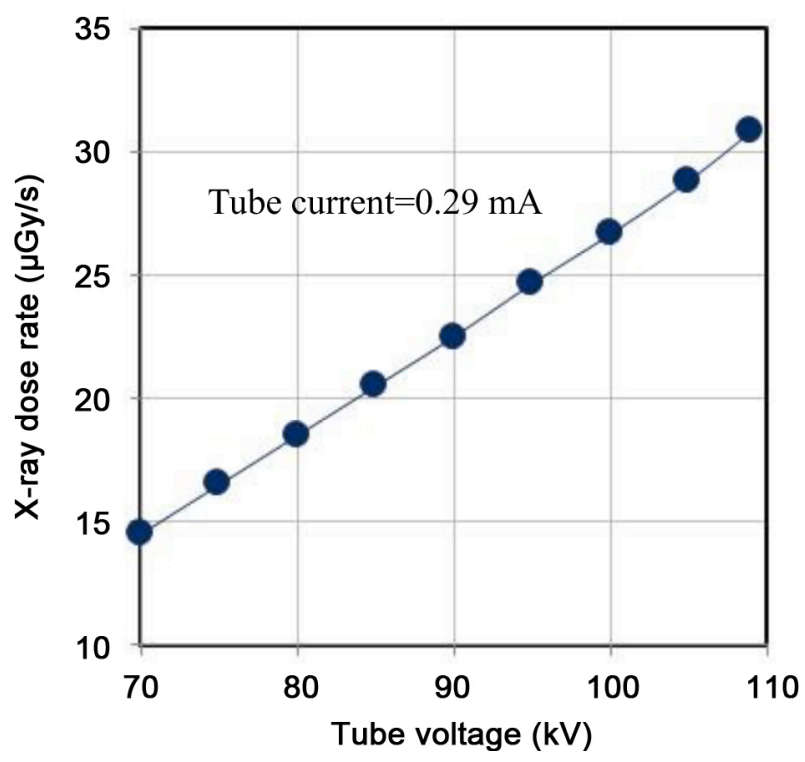

Figure 5. X-ray dose rate measured at $1.00 \mathrm{~m}$ from the X-ray source and a tube current of $0.29 \mathrm{~mA}$.

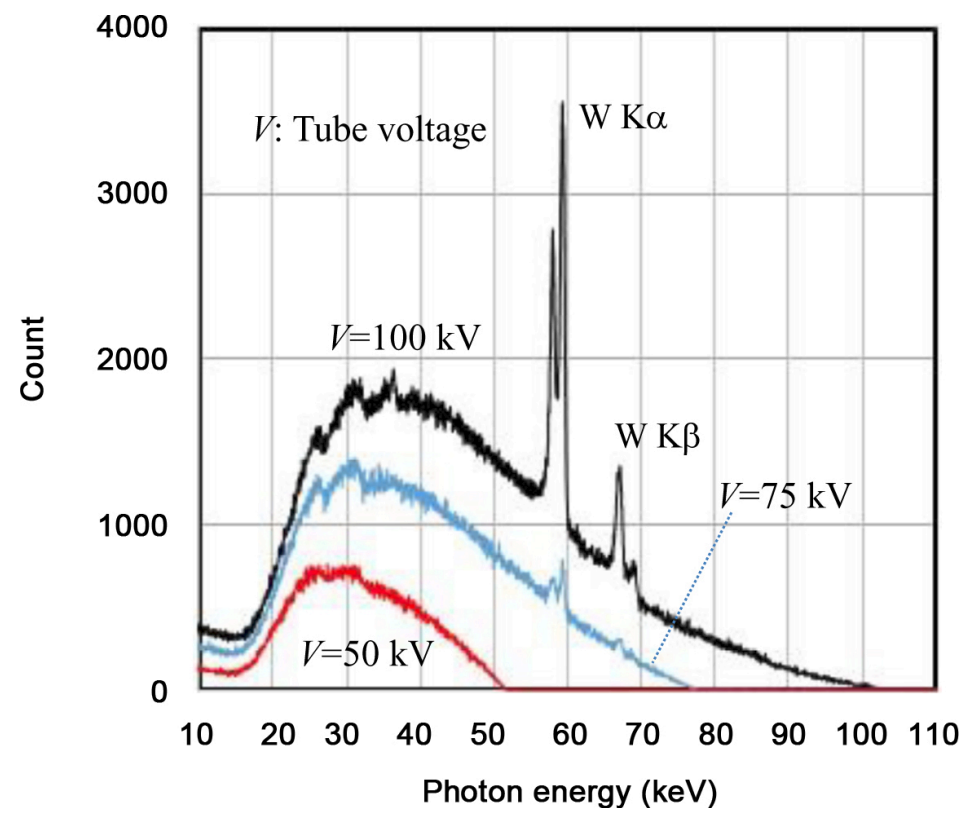

Figure 6. Standard X-ray spectra measured using a CdTe detector with changes in the tube voltage.

observed W-K photons.

Figure 7 shows the X-ray spectra measured using the LSO-PMT detector. The $\mathrm{L}_{\mathrm{I}^{-}}$and $\mathrm{K}$-edge energies are shown for reference and have values of 8.4 and 50.2 $\mathrm{keV}$, respectively. Both the maximum and bremsstrahlung-peak energies increased with increases in the tube voltage. The bremsstrahlung-peak energy corresponded well to that of standard spectra at a tube voltage of $50 \mathrm{kV}$. At a tube voltage of $100 \mathrm{kV}$, we confirmed the irradiation of $\mathrm{W}-\mathrm{K} \alpha$ photons, and the peak energy was slightly lower than the average K $\alpha$ energy of $58.9 \mathrm{keV}$.

Figure 8 shows selected X-ray spectra for DE-CT, and the photons with ener- 


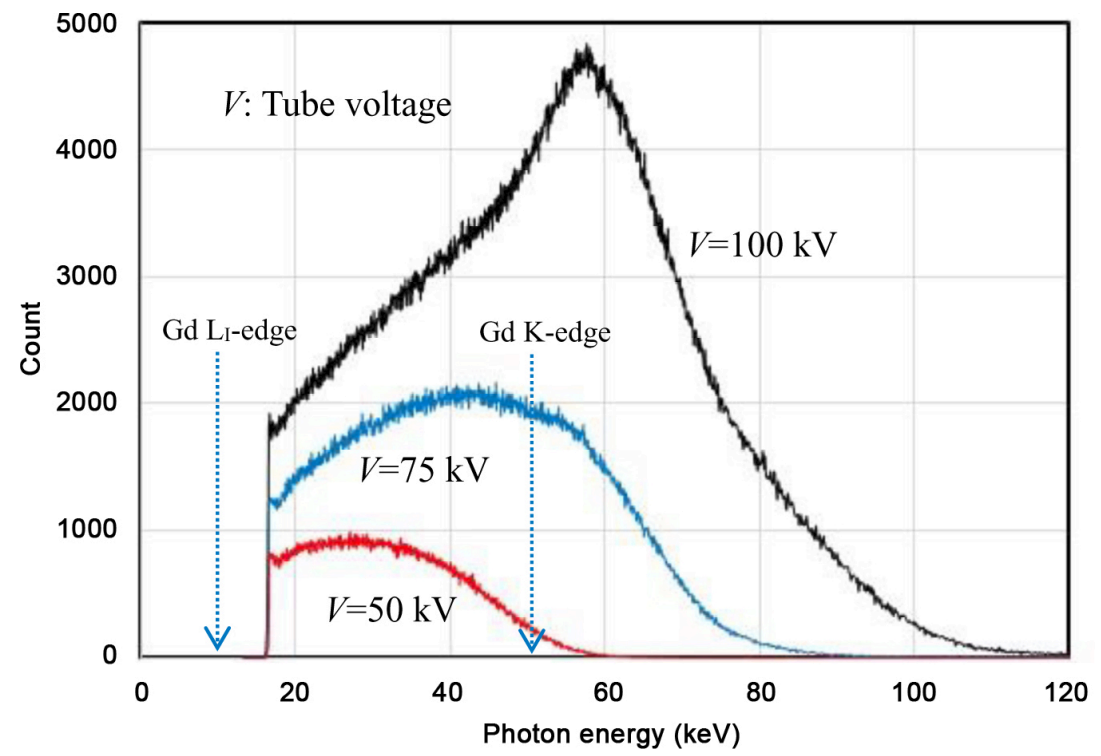

Figure 7. X-ray spectra measured using the LSO-PMT detector in the DE-CT scanner with changes in the tube voltage. $\mathrm{Gd}_{-} \mathrm{L}_{\mathrm{I}^{-}}$and $\mathrm{K}$-edge energies are shown in the same figure for reference.

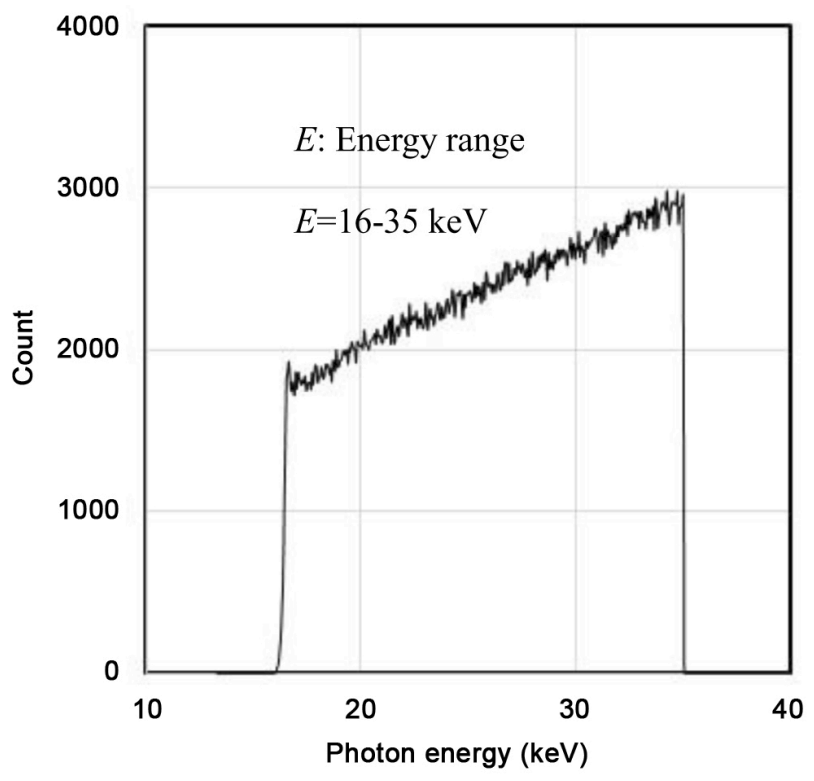

(a)

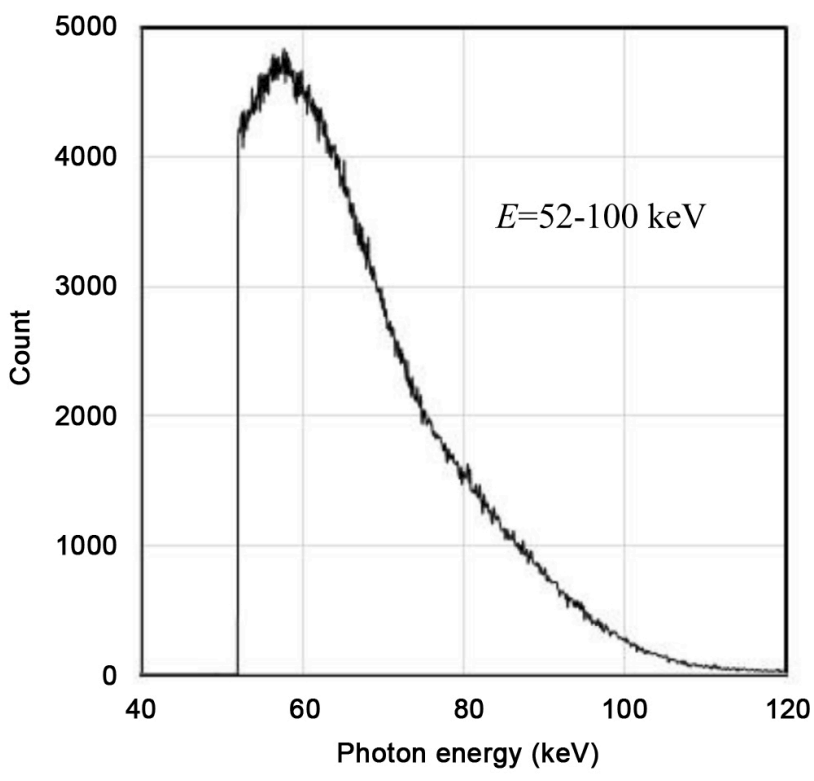

(b)

Figure 8. Selected X-ray spectra for DE-CT at a tube voltage of $100 \mathrm{kV}$. (a) X-ray photons with energies ranging from 16 to $35 \mathrm{keV}$ for Gd-L-edge CT and (b) photons ranging from 52 to $100 \mathrm{keV}$ for Gd-K-edge CT.

gies ranging from 16 to $35 \mathrm{keV}$ are useful for performing Gd-L-edge CT because these photons with energies beyond $\mathrm{Gd}-\mathrm{L}_{\mathrm{I}}$-edge are absorbed effectively by $\mathrm{Gd}$ atoms. On the contrary, photons at a range of $52-100 \mathrm{keV}$ are useful for carrying out Gd-K-edge CT. The photon count rates at the two ranges of $16-35$ and $52-100 \mathrm{keV}$ were 26 and $68 \mathrm{kcps}$, respectively.

\subsection{Tomography}

Tomography was performed at a constant tube voltage of $100 \mathrm{kV}$ and a tube 
current of $0.29 \mathrm{~mA}$. Tomograms are obtained as JPEG files, and the maximum and minimum gray-value densities are defined as 255 (white) and 0 (black), respectively.

Tomograms of two glass vials filled with Gd media (meglumine gadopentetate) of two different Gd densities of 15 and $30 \mathrm{mg} / \mathrm{ml}$ are shown in Figure 9. The gray-value density analysis using a program Image $J$ is shown in the same figure. Using a range of $16-35 \mathrm{keV}$, it was easy to image glass vials, and the density difference between two media was large. At a range of $52-100 \mathrm{keV}$, it was not easy to image the vials, and the density difference between the two media slightly increased. In both tomograms, the artifacts could be observed between the vials.

Figure 10 shows the result of the tomography of a polymethyl methacrylate (PMMA) phantom with two holes filled with Gd media of two different densities

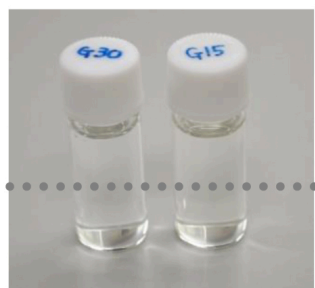

15-mm-diameter glass vials

Gd-L-edge CT 16-35 keV
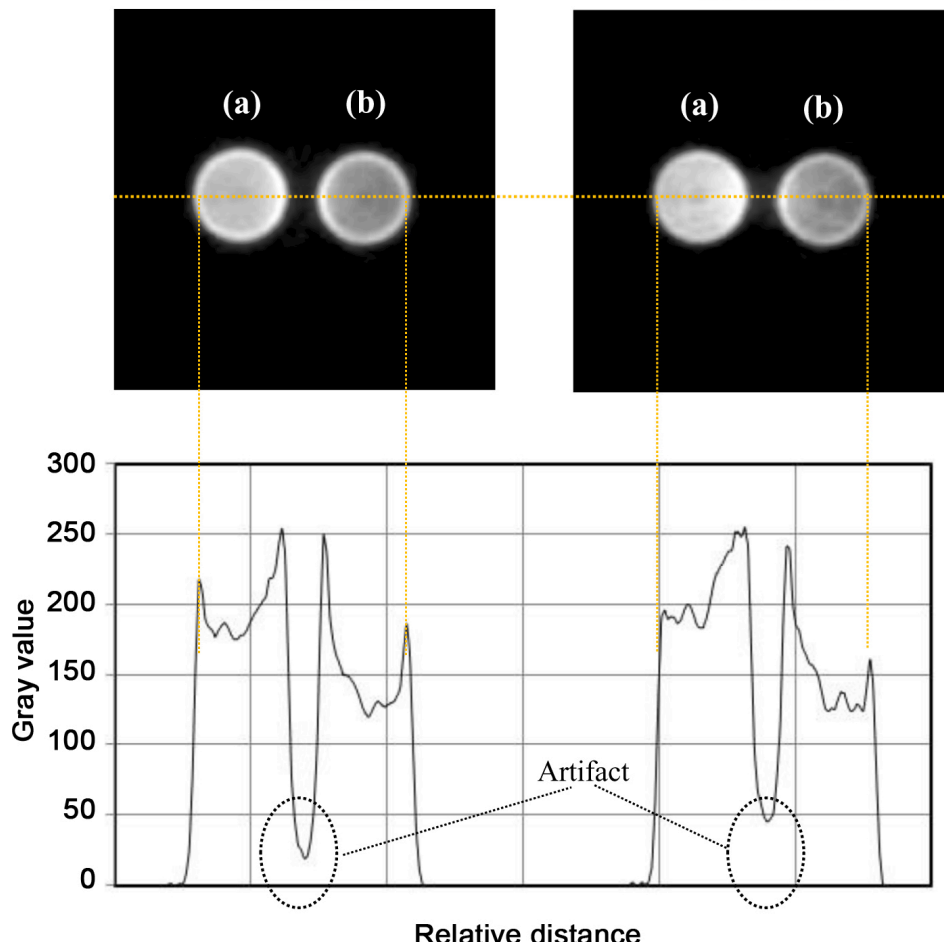

(a) $30 \mathrm{mg} / \mathrm{ml} \mathrm{Gd}$

(b) $15 \mathrm{mg} / \mathrm{ml} \mathrm{Gd}$

$60 \mathrm{~mm}$

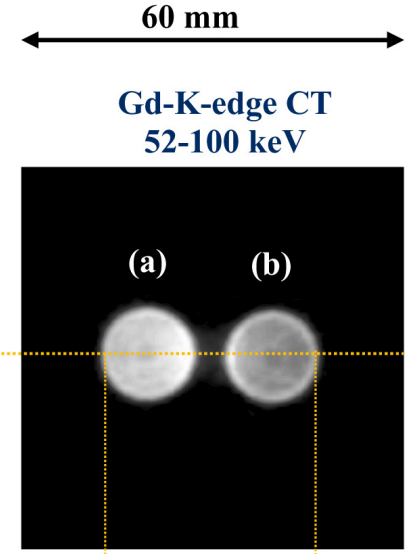

Gd-K-edge CT 


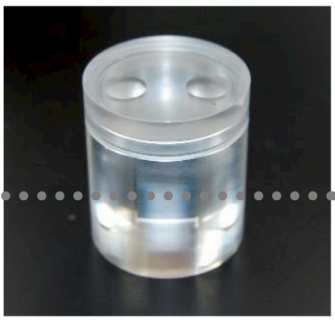

PMMA phantom

Gd-L-edge CT $16-35 \mathrm{keV}$

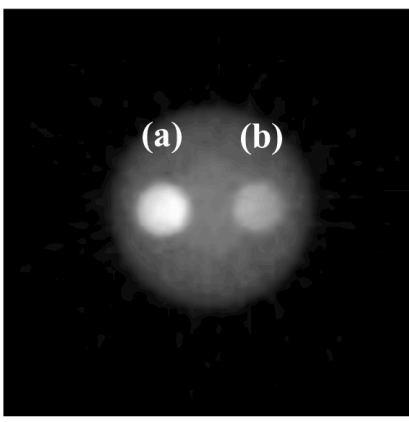

(a) $30 \mathrm{mg} / \mathrm{ml} \mathrm{Gd}$

(b) $15 \mathrm{mg} / \mathrm{ml} \mathrm{Gd}$

$60 \mathrm{~mm}$

Gd-K-edge CT

$52-100 \mathrm{keV}$

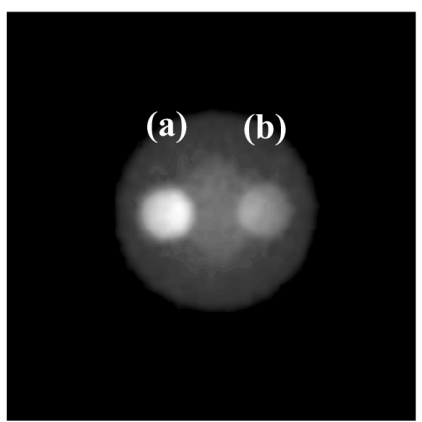

Figure 10. Tomography of a PMMA phantom with two holes filled with Gd media of two different densities of 15 and $30 \mathrm{mg} / \mathrm{ml}$. Using the Gd-K-edge CT, the PMMA density decreased, and the Gd media are seen at high contrasts.

of 15 and $30 \mathrm{mg} / \mathrm{ml}$. Using L-edge CT at a range of $16-35 \mathrm{keV}$, the PMMA density was high, and the image density difference between two media was large. Subsequently, the PMMA density decreased, and the image density difference between the two media was also large utilizing Gd-K-edge CT.

Figure 11 shows the result of the tomography of a rabbit-head phantom. The blood vessels were filled with gadolinium oxide $\left(\mathrm{Gd}_{2} \mathrm{O}_{3}\right)$ microparticles. Radiography (angiography) was performed for reference using a flat-panel detector (FPD; Rad-icon Imaging, $1024 \mathrm{EV}$ ) to observe blood vessels. In radiography, fine blood vessels were observed with pixel sizes of $48 \times 48 \mu \mathrm{m}^{2}$. In the Gd-L-edge CT at the energy range of $16-35 \mathrm{keV}$, the image densities of bones and muscles were high, and blood vessels were observed. Using Gd-K-edge CT at a range of $52-100 \mathrm{keV}$, the muscle and bone densities decreased, and the image contrast of thick vessels was substantially improved.

\section{Discussion}

We performed DE X-ray photon counting using an LSO-PMT detector at a maximum count rate of $105 \mathrm{kcps}$ and an entire energy range of $16-100 \mathrm{keV}$. Therefore, the maximum count per measuring point was 2.1 kilocounts with a scan step of $0.5 \mathrm{~mm}$ and an LSO-PMT scan velocity of $25 \mathrm{~mm} / \mathrm{s}$.

At a constant tube voltage of $100 \mathrm{kV}$, the photon count rate for DE-CT is proportional to the dose rate. The dose rate was increased to obtain the maximum count rate without pileups of event pulses by increasing the tube current to $0.29 \mathrm{~mA}$. 


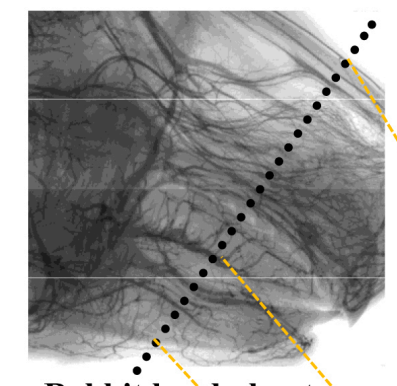

Tube voltage $=100 \mathrm{kV}$

$E$ : Energy range
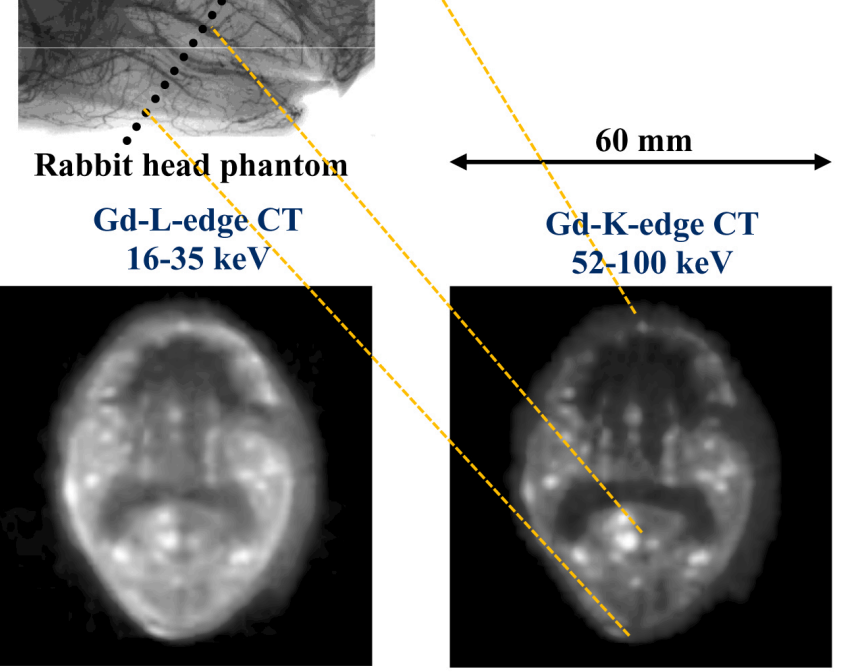

Figure 11. Tomography of a rabbit-head phantom. The blood vessels were filled with $\mathrm{Gd}_{2} \mathrm{O}_{3}$ microparticles. Using Gd-K-edge CT, thick blood vessels were visible.

Although we are performing a DE-CT using a CdTe array detector made by $\mathrm{XCounter}$, the first-generation energy-dispersive CT with the single detector is useful for carrying out fundamental experiments concerning various photon counting detectors, confirming the imaging effect with changes in the detector, and reducing the cost of the CT scanner.

The photon energy ranges of Gd-L- and K-edge tomograms were 16 - 35 and $52-100 \mathrm{keV}$, respectively, and the maximum counts for the two tomograms per measuring point were approximately 0.5 and 1.4 kilocounts, respectively. In particular, Gd-L-edge CT is of a novel soft X-ray imaging, and blood vessels can be seen at high contrasts.

To determine the photon energy using the LSO-PMT detector, we performed brief four-point calibration including the maximum photon energies of bremsstrahlung spectra. However, two-point calibration can be used when only the DE-CT is carried out; the detector sensitivity substantially varies beyond LuK-edge. Although the minimum photon energy detected using the LSO-PMT detector was $16 \mathrm{keV}$, the minimum detectable energy can be reduced by increasing the bias voltage of the PMT without the saturation of sensitivity.

The scan step was $0.5 \mathrm{~mm}$, and the pixel dimensions of the reconstructed tomograms were also $0.5 \times 0.5 \mathrm{~mm}^{2}$. Next, the pinhole diameter primarily determined the spatial resolutions of approximately $0.5 \times 0.5 \mathrm{~mm}^{2}$, and the image quality improves with decreasing scan and rotation steps. Although the resolutions were $1.0 \times 1.0 \mathrm{~mm}^{2}$ in our former research [15] using a CdTe detector and a cone beam, the image quality has substantially improved by improving the resolutions in this research. 
We have also constructed several first-generation energy-dispersive CT scanners using high-energy-resolution CdTe detectors to confirm the imaging effect with changes in the energy range. In the near future, the spatial resolutions will be improve to approximately $0.25 \times 0.25 \mathrm{~mm}^{2}$ using the pinhole. However, it is not easy to construct a preclinical energy-dispersive CT scanner owing to long exposure times. In this regard, we are constructing a DE-CT scanner using a CdTe array detector made by XCounter [9] with pixel dimensions of $0.1 \times 0.1$ $\mathrm{mm}^{2}$, and 3-diamntional DE-CT will be carried out soon.

\section{Conclusion}

We developed a high-rate DE photon counter consisting of an LSO-PMT detector system, three comparators, and two sets of MCs and FVCs. We also constructed a first-generation DE-CT scanner with two different energy selectors. At a tube voltage of $100 \mathrm{kV}$ and a current of $0.29 \mathrm{~mA}$, we performed Gd-L- and K-edge CT simultaneously. Both the spatial and the energy resolutions will be improved in the near future, and fine blood vessels can be observed at high contrasts. The DE counter can be used effectively in several X-ray imaging systems for observing a wide variety of biomedical objects.

\section{Acknowledgements}

This work was supported by Grants from Keiryo Research Foundation, Promotion and Mutual Aid Corporation for Private Schools of Japan, Japan Science and Technology Agency (JST), and JSPS KAKENHI (17K10371, 17K09068, 17K01424, 17H00607). This was also supported by a Grant-in-Aid for Strategic Medical Science Research (S1491001, 2014-2018) from the Ministry of Education, Culture, Sports, Science and Technology of Japan.

\section{References}

[1] Mori, H., Hyodo, K., Tanaka, E., Uddin-Mohammed, M., Yamakawa, A., Shinozaki, Y., Nakazawa, H., Tanaka, Y., Sekka, T., Iwata, Y., Handa, S., Umetani, K., Ueki, H., Yokoyama, T., Tanioka, K., Kubota, M., Hosaka, H., Ishikawa, N. and Ando, M. (1996) Small-Vessel Radiography In Situ with Monochromatic Synchrotron Radiation. Radiology, 201, 173-177. https://doi.org/10.1148/radiology.201.1.8816540

[2] Hyodo, K., Ando, M., Oku, Y., Yamamoto, S., Takeda, T., Itai, Y., Ohtsuka, S., Sugishita, Y. and Tada, J. (1998) Development of a Two-Dimensional Imaging System for Clinical Applications of Intravenous Coronary Angiography Using Intense Synchrotron Radiation Produced by a Multipole Wiggler. Journal of Synchrotron Radiation, 5, 1123-1126. https://doi.org/10.1107/S0909049597017639

[3] Sato, E., Tanaka, E., Mori, H., Kawai, T., Ichimaru, T., Sato, S., Takayama, K. and Ido, H. (2004) Demonstration of Enhanced K-Edge Angiography Using a Cerium Target X-Ray Generator. Medical Physics, 31, 3017-3022. https://doi.org/10.1118/1.1803433

[4] Watanabe, M., Sato, E., Abderyim, P., Abudurexiti, A., Hagiwara, O., Matsukiyo, H., Osawa, A., Enomoto, T., Nagao, J., Sato, S., Ogawa, A. and Onagawa, J. (2011) First Demonstration of $10 \mathrm{keV}$-Width Energy-Discrimination K-Edge Radiography Using a Cadmium-Telluride X-Ray Camera with a Tungsten-Target Tube. Nuclear 
Instruments and Methods in Physics Research Section A, 637, 171-177.

[5] Yanbe, Y., Sato, E., Chiba, H., Maeda, T., Matsushita, R., Oda, Y., Hagiwara, O., Matsukiyo, H., Osawa, A., Enomoto, T., Watanabe, M., Kusachi, S., Sato, S. and Ogawa, A. (2013) High-Sensitivity High-Speed X-Ray Fluorescence Scanning Cadmium Telluride Detector for Deep-Portion Cancer Diagnosis Utilizing TungstenKa-Excited Gadolinium Mapping. Japanese Journal of Applied Physics, 52, 092201 1-4. https://doi.org/10.7567/JJAP.52.092201

[6] Feuerlein, S., Roessl, E., Proksa, R., Martens, G., Klass, O., Jeltsch, M., Rasche, V., Brambs, H.J., Hoffmann, M.H.K. and Schlomka, J.P. (2008) Multienergy Photon-Counting K-Edge Imaging: Potential for Improved Luminal Depiction in Vascular Imaging. Radiology, 249, 1010-1016. https://doi.org/10.1148/radiol.2492080560

[7] Ogawa, K., Kobayashi, T., Kaibuki, F., Yamakawa, T., Nanano, T., Hashimoto, D. and Nagaoka, H. (2012) Development of an Energy-Binned Photon-Counting Detector for X-Ray and Gamma-Ray Imaging. Nuclear Instruments and Methods in Physics Research Section A, 664, 29-37. https://doi.org/10.1016/j.nima.2011.10.009

[8] Taguchi, K. (2017) Energy-Sensitive Photon Counting Detector-Based X-Ray Computed Tomography. Radiological Physics and Technology, 10, 8-22. https://doi.org/10.1007/s12194-017-0390-9

[9] Zscherpel, U., Walter, D., Redmer, B., Ewert, U., Ullberg, C., Weber, N. and Pantsar, T. (2014) Digital Radiology with Photon Counting Detectors. Proc. 11 th Europian Conference on Non-Destructive Testing, Prague, 6-10 October 2014. http://www.ndt.net/events/ECNDT2014/app/content/Paper/461_Zscherpel.pdf

[10] Matsukiyo, H., Sato, E., Hagiwara, O., Abudurexiti, A., Osawa, A., Enomoto, T., Watanabe, M., Nagao, J., Sato, S., Ogawa, A. and Onagawa, J. (2011) Application of an Oscillation-Type Linear Cadmium Telluride Detector to Enhanced Gadolinium K-Edge Computed Tomography. Nuclear Instruments and Methods in Physics Research Section A, 632, 142-146. https://doi.org/10.1016/j.nima.2010.12.211

[11] Sato, E., Oda, Y., Abudurexiti, A., Hagiwara, O., Matsukiyo, H., Osawa, A., Enomoto, T., Watanabe, M., Kusachi, S., Sato, S., Ogawa, A. and Onagawa, J. (2012) Demonstration of Enhanced Iodine K-Edge Imaging Using an Energy-Dispersive X-Ray Computed Tomography System with a $25 \mathrm{~mm} / \mathrm{s}$-Scan Linear Cadmium Telluride Detector and a Single Comparator. Applied Radiation and Isotopes, 70, 831836. https://doi.org/10.1016/j.apradiso.2012.02.007

[12] Hagiwara, O., Sato, E., Watanabe, M., Sato, Y., Oda, Y., Matsukiyo, H., Osawa, A., Enomoto, T., Kusachi, S. and Ehara, S. (2014) Investigation of Dual-Energy X-Ray Photon Counting Using a Cadmium Telluride Detector and Two Comparators and Its Application to Photon-Count Energy Subtraction. Japanese Journal of Applied Physics, 53, 102202-1-6. https://doi.org/10.7567/jjap.53.102202

[13] Sato, E., Sugimura, S., Endo, H., Oda, Y., Abudurexiti, A., Hagiwara, O., Osawa, A., Matsukiyo, H., Enomoto, T., Watanabe, M., Kusachi, S., Sato, S., Ogawa, A. and Onagawa, J. (2012) 15 Mcps Photon-Counting X-Ray Computed Tomography System Using a $\mathrm{ZnO}-\mathrm{MPPC}$ Detector and Its Application to Gadolinium Imaging. $A p$ plied Radiation and Isotopes, 70, 336-340.

https://doi.org/10.1016/j.apradiso.2011.07.002

[14] Wakabayashi, G., Nohtomi, A., Yahiro, E., Fujibuchi, T., Fukunaga, J., Umezu, Y., Nakamura, Y., Nakamura, K., Hosono, M. and Itoh, T. (2015) Applicability of Self-Activation of an NaI Scintillator for Measurement of Photo-Neutrons around a High-Energy X-Ray Radiotherapy Machine. Radiological Physics and Technology, 8, 125-134. https://doi.org/10.1007/s12194-014-0300-3 
[15] Sato, E., Kosuge, Y., Yamanome, H., Mikata, A., Miura, T., Oda, Y., Ishii, T., Hagiwara, O., Matsukiyo, H., Watanabe, M. and Kusachi, S. (2017) Investigation of Dual-Energy X-Ray Photon Counting Using a Cadmium Telluride Detector with Dual-Energy Selection Electronics. Radiation Physics and Chemistry, 130, 385-390. https://doi.org/10.1016/j.radphyschem.2016.09.018

\section{Scientific Research Publishing}

Submit or recommend next manuscript to SCIRP and we will provide best service for you:

Accepting pre-submission inquiries through Email, Facebook, LinkedIn, Twitter, etc. A wide selection of journals (inclusive of 9 subjects, more than 200 journals) Providing 24-hour high-quality service User-friendly online submission system Fair and swift peer-review system Efficient typesetting and proofreading procedure Display of the result of downloads and visits, as well as the number of cited articles Maximum dissemination of your research work

Submit your manuscript at: http://papersubmission.scirp.org/ Or contact ijmpcero@scirp.org 